\title{
Prevalence of Intestinal Parasitosis in Children of a Primary School in Pedro Juan Caballero - PY
}

\author{
Kayque Wellek Delgado do Amaral ${ }^{1}$; Cristiane Venturini Garlet ${ }^{1}$; Daniel Contreira Júnior ${ }^{1}$; Marcus Tadeu \\ Fernandes Gomes da Silva ${ }^{1}$; Laura Simões Cogorno ${ }^{1}$; Luiz Eduardo Lorenzoni Brandão ${ }^{1}$; Danilo Pigosso \\ Marciano $^{1}$; João Miguel Militão da Silva ${ }^{1}$; Rebecca Corrêa Manfredini ${ }^{2}$; João Italo Fortaleza de Melo ${ }^{2}$ \\ ${ }^{1}$ Faculty of Medicine- Pacific University-UP-Pedro Juan Caballero-PY \\ ${ }^{2}$ Cerdil-Center for Radiology and Diagnostic Imaging-Dourados -Brazil
}

Corresponding author: Rua Porto Esperança; kayquewdamaral@gmail.com

Received 12 September 2020;

Accepted 28 September 2020;

Published 01 October 2020

\begin{abstract}
Introduction: Parasitosis is a type of endoparasitism, which is directly related to sanitary conditions and is an important public health problem in developing countries. Objective: To determine the prevalence of intestinal parasites in children attending a primary public school in Pedro Juan Caballero - PY. Materials and Methods: 85 (eighty-five) stool samples were analyzed using the centrifugal sedimentation technique. Results: Cysts and/or parasite eggs were observed in the stool samples of 67 (78.8\%) children. Giardia lamblia cysts were those that showed the highest incidence in the children. Conclusion: The high Giardia lamblia index demonstrates the lack of access to drinking water for consumption, inadequate sanitation and the absence of a public health network. This study highlights the importance of encouraging the use of serial analysis of stool, strengthening preventive measures for parasitosis, developing protocols for their approach, and designing a strategy that includes the preschool population in the programs that periodically evaluate the development of children.
\end{abstract}

Keywords: Enteroparasites. Prevalence Helminths. Cysts Protozoa.

\section{Introduction}

Parasitosis is a type of endoparasitism, which is closely related to sanitary conditions and a major public health problem in developing countries, where they are endemic, contributing to economic and social problems ${ }^{[1]}$. Neglecting principles of personal hygiene and care in food preparation facilitates infection and reinfection in endemic areas ${ }^{[2]}$.

When it comes to basic sanitation, one of the many parameters used to assess the living conditions of the population is the performance of parasitological studies and the high prevalence of these parasites indicates the necessity to adopt sanitation measures for the population ${ }^{[3]}$.

The pathogenic intestinal parasites are among the most frequent parasites found in humans, they constitute a serious health injury. Among the helminths, the most frequent are the nematodes Ascaris lumbricoides, Trichuris trichiura and Ancylostoma. Among the protozoa, Entamoeba histolytica and Giardia lamblia stand out. The World Health Organization estimates that there are, worldwide, approximately 1 million people infected with $A$. lumbricoides, and only slightly fewer people infected with $T$. trichiura and Ancylostoma. It is also estimated that between 200 and 500 million people, respectively, possess G. lamblia and E. histolytica ${ }^{[4]}$.
The warm environment of tropical countries associated with malnutrition, lack of medical assistance, contamination of food and water, poor sanitary conditions, the presence of reservoirs and vectors, inadequate personal and domestic hygiene practices are factors that promote the development and spread of infectious helminth forms and intestinal protozoa ${ }^{[5]}$.

The appearance of intestinal parasites in childhood, especially in school age, is an aggravating factor of malnutrition and can lead to nutritional morbidity, usually accompanied by chronic diarrhea and malnutrition, affecting, as a consequence, the physical and intellectual development, particularly the youngest age groups of the population ${ }^{[4]}$. This research is aimed to determine the prevalence of intestinal parasites in children of a primary public school in Pedro Juan Caballero - PY.

\section{Materials and Methods}

It is a descriptive observational research of a quantitative nature. It happened in a public Primary School in the city of Pedro Juan Caballero-PY. The sample of the investigation consisted of 85 students from 4 to 12 years of age.

The study began with a visit to the school to request authorization and collaboration for the execution of the research. Then, at another time, a meeting was held with parents and 
preschool-age students to explain the objective of the investigation, the development and continuation of the investigation, the necessary instructions for the collection and storage of the sample, requesting their collaboration and signature of the authorization forms, respecting the ethical standards of research. 100 Collection kits for feces (containing collection bottles, spoons and instructions for collection and storage of the sample) were delivered. In addition, the dates for the delivery of the results were scheduled.

On the day of collection of the samples, all the members of the group were present. In two days, a total of 85 (eighty-five) samples were collected. The jars were properly labeled and stored. The samples were stored and later analyzed in the Microbiology and Parasitology laboratory of the University, using the centrifugal sedimentation technique that consisted in the preparation, analysis and cleaning of the materials. The data were collected in a spreadsheet, tabulated in Excel and analyzed using the relative frequency formula and the results expressed as a percentage.

\section{Results}

Of the total of 100 (one hundred) collection kits delivered, 85 (eighty-five) samples were collected in the two days that the group was in school, of which $38(43.5 \%)$ were female and 47 (56.5\%) male. The ages vary from 4 to 12 years and their weights spread from 13.7 to $58.3 \mathrm{Kg}$. The mean age is approximately 7 years and the mean weight is $26.64 \mathrm{Kg}$.

In the analyzes, cysts and/or parasite eggs were observed in the stool samples of 67 (sixty-seven) children, that is, in $78.8 \%$ of the observed children and in 18 (eighteen) children, 21.2\%, the result was negative (Graph 1).

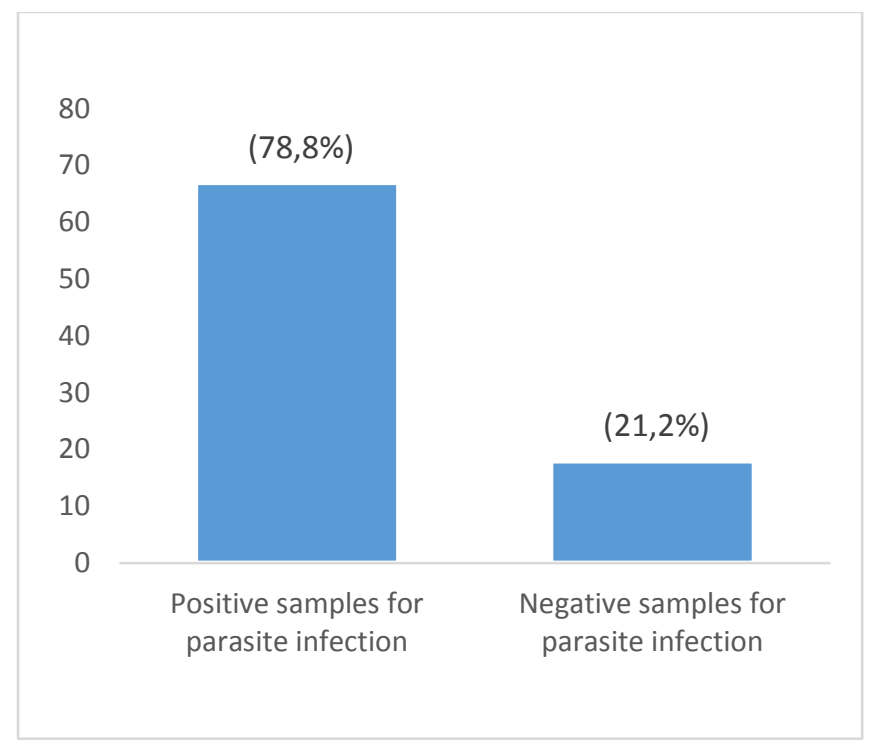

Graph 1. Prevalence of parasitosis in the observed samples.

Among the 67 (sixty-seven) positive samples, there was a prevalence of Giardia lamblia cysts in57 children (67\%). In addition, Entamoeba coli cysts (14\%) and, Entamoeba hystolitica (1\%), Endolimax nana (3.5\%), Hymenolepis nana eggs (4.7\%) and vacuolated forms of Blastocystis hominis (11.7\%) were observed. In 18 (eighteen) samples, $21 \%$, more than one type of parasite was observed (Graph 2). Of the 67 children evaluated, 17 presented two parasites and one, three parasites (Table 1).
Entamoeba hystolitica

Endolimax nana

- Hymenolepis nana

- Blastocytis hominis

Entamoeba coli

No observados

Giardia lamblia

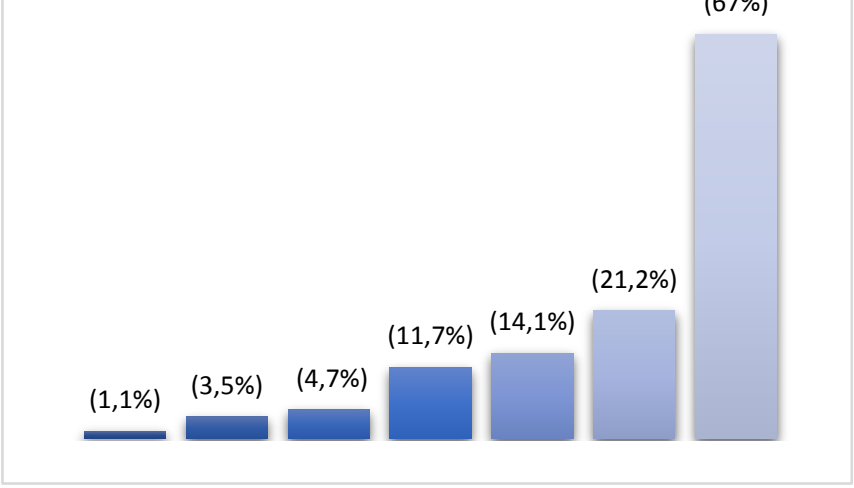

Graph 2: Parasites observed in the stool samples.

Table 1: Number of children and the correspondence with the number of parasites observed.

\begin{tabular}{|l|l|l|}
\hline Number of children & number of parasites & Percentage (\%) \\
\hline 67 & 1 & $78,8 \%$ \\
\hline 17 & 2 & $20 \%$ \\
\hline 1 & 3 & $1,2 \%$ \\
\hline
\end{tabular}

\section{Discussion}

This data demonstrates a high rate of parasite infections in schoolage children. This high index can compromise the mental and physical health of the children in addition to damaging the nutritional intake and the learning process of the children ${ }^{[6]}$.

Studies have shown that in developing countries the average parasitosis is around 30 to $50 \%$, these figures are directly related to the hygienic and sanitary conditions present in the population with serious socioeconomic problems such as: poor quality of drinking water, inadequate final disposal of liquid and solid waste, very low educational level, overcrowding, among other factors,. As is known, the health status of people depends on the interaction with the environment in which they live and on the behavior that is followed ${ }^{[6]}$.

In this study, the evaluated site presented poor water quality, a large part of the population does not consume treated water, does not have a sewage network and the water storage does not have adequate quality. All these scenarios may have mainly contributed to the high prevalence of the Giardia lamblia parasite $(67 \%)$ in children. Studies have shown that this parasite has its evolutionary cycle mainly in contaminated water ${ }^{[7]}$. The origin, storage, treatment and handling of water are essential requirements that must be met for it to have an optimal quality when consumed, preventing the spread of those parasites.

It is known that children in the studied developmental phase do not have adequate knowledge about the importance of hygiene habits, which favors the transmission of those parasites by water, fruits, vegetables, or even by objects or parts of the body taken to the mouth and also by person to person contamination, resulting from large families living in the same household, with a high prevalence of infected adults, increasing risk of child contamination $^{[8]}$. 
It is important to reinforce the role of parents' education over their children's health. Studies show that the level of education of two parents has a direct influence on access to information and education concerning the hygiene habits of the child. The Carvalho et al (2002) ${ }^{[9]}$ study highlighted the lower the level of maternal education, the higher the rate of parasite infection in children.

Despite the fact that intestinal parasitosis is a preventable and treatable disease, there are still weaknesses in its approach. Some of those weaknesses include: lack of a standardized protocol for the care of parasites, few therapeutic options (albendazole, metronidazole, and ivermectin), little research on the subject, and poor training of health personnel in the care and treatment of those diseases. Another significant debility is that an empirical treatment for intestinal parasites is commonly provided, which is rarely supported by a prior demonstration of parasite infection ${ }^{[7,10,11]}$.

\section{Conclusion}

With the present investigation it was possible to conclude that more than $75 \%$ of the children presented parasites, being cysts, especially Giardia Lamblia, the most prevalent. The high Giardia lamblia index demonstrates the lack of access to drinking water for consumption, inadequate sanitation and the absence of a public health network. In addition, community use of wash basins for hand and face washing increases and facilitates the spread of parasitosis. This study highlights the importance of encouraging the use of serial analysis of feces, strengthening preventive measures for parasitosis, developing protocols for their approach, and designing a strategy that includes the preschool population within the programs that assess the development of children periodically.

\section{Data Availability}

All data in qualitative character, used by our work, as well as spreadsheets, images and others that support the results and conclusions of this study are readily available through the corresponding author.

\section{Conflicts of Interest}

The authors have no conflict of interest to declare.

\section{Funding Statement}

There was no financial support from any public or private institution for this research. The activities of this research were conducted using the authors in partnership.

\section{Authors' contributions}

The initial proposal was made by the KWDA and approved by all authors after submitting the research topic to a wide discussion and a better reformulation. DCJ conducted the literature review and collected all relevant data. CVG performed the data analysis. The Manuscript was written by KWDA, revised by all authors who agreed with its content and made the collective decision to submit it for consideration and possible publication.

\section{Reference}

[1] Zochio LB, Chaves PC, Monteiro CP, Fontolan OL, Dalpino D. Prevalência de Parasitas Intestinais em Crianças do Centro de Convivência Infantil e da EMEI Venâncio Ramalho Guedes de Azevedo do Instituto "Lauro de Souza Lima" (ILSL). Bauru/SP. Newslab. 2006.

[2] Andrade EC, Leite ICG, Rodrigues VO, Cesca MG. Parasitoses Intestinais: Uma revisão sobre seus aspectos sociais, epidemiológicos, Clínicos e Terapêuticos. Revista APS 2010;(13):231-240.

[3] Castro AZ, Viana JDC, Penedo AA, Donatele DM. Levantamento das Parasitoses Intestinais em Escolares da Rede Pública na Cidade de Cachoeiro de Itapemirim ES. NewsLab 2004.

[4] Falavigna GAL, Aráujo SM, Pupulin ART, Lima Júnior JE, Falavigna DLM. Parasitos intestinais e comensais em indivíduos de três Vilas Rurais do Paraná, Brasil. Acta Sci. 2004;26(2):331-6.

[5] Costa MCE, Macedo LMC, Almeida LM. Parasitismo por Ascaris lumbricoides em crianças menores de dois anos: estudo populacional em comunidade do estado do Rio de Janeiro. Cadernos Saúde Pública. 2005;15(1):173178.

[6] Lucero T, Álvarez L, Chicue J, López D, Mendoza C. Parasitosis intestinal y factores de riesgo en niños de los asentamientos subnormales, Florencia- Caquetá, Colombia. Rev Fac Nac Salud Pública. 2015; 33:171-80.

[7] Solano M, Montero SA, León AD, Santamaría UC, Mora AM., Reyes LL. Prevalencia de parasitosis en niños de 1 a 7 años en condición de vulnerabilidad en la Región Central Sur de Costa Rica. Acta méd. Costarric. 2018;60(2): 19-29.

[8] Vasconcelos IAB, Oliveira, JW, Cabral FRF, Coutinho, HDM, Menezes IRA. Prevalência de parasitoses intestinais entre crianças de 4-12 anos no Crato, Estado do Ceará: um problema recorrente de saúde pública. Acta Scientiarum. Health Sciences, 2011:33(1), 35-41.

[9] Carvalho OS, Guerra HL, Campos Y R, Caldeira RL, Massara CL. Prevalência de helmintos intestinais e três mesorregiões do estado de Minas Gerais. Revista da Sociedade Brasileira de Medicina Tropical, 2002; 35(6): 601-607.

[10] Vásquez LCO. Parasitosis y antiparasitarios en niños. Medicina UPB, 2019;38(1): 46-56.

[11] Yelisa DP, Zulbey RR. Angela BM. Prevalencia de parasitosis intestinales en niños del Cantón Paján, Ecuador. Revista Kasmera, 2019; 47(1). 